\title{
Traumatic lumbar spondylolisthesis without facet fracture at L4/L5. A case report and literature review
}

\author{
Dominique N'Dri-Oka*', Souleymane Issa Sarki, Landry Konan and Yacouba Haro
}

\begin{abstract}
$\mathrm{L} 4-\mathrm{L} 5$ traumatic spondylolisthesis has been rarely reported in the literature. At lumbar spine level traumatic dislocation lesion realizes "traumatic spondylolisthesis or traumatic bilateral lumbar facet locked syndrome". The aim of the present paper is to report this rare lesion and discuss its mechanism and management. A case report is followed by Literature review made on Medline and scholar google database from 2000 to 2015. The case report concerned a 33-year-old man, who refused to wear a seat belt, injured his lumbar spine following a motor vehicle accident. L4-L5 spondylolisthesis occurred after the vehicle rolled over several times. Sixteen months after the accident the patient had a favorable outcome. Literature review on Medline and scholar google database from 2000 to 2015 was carried out and five cases of traumatic spondylolisthesis were found. The Sex ratio was 3/2. Surgical treatment consisted of posterolateral interbody fusion.

Traumatic lumbar spine spondylolisthesis is rare. When it occurs, it is always associated with vertebral lumbar fracture. L4-L5 traumatic spondylolisthesis was caused by a high-energy mechanism and improper use of seat belt.
\end{abstract}

Keywords: Spondylolisthesis at L4-L5, Bilateral facet locked syndrome at L4-L5, Lumbar spine trauma

\section{Background}

Traumatic spondylolisthesis is an uncommon entity reported in the literature. Watson-Jones described the first case in 1940 and about hundred cases reported [1]. All reported cases are traumatic lumbosacral dislocations; this represents a dislocation on L5-S1 level. The lumbar spine pure traumatic spondylolisthesis realizes "traumatic bilateral lumbar facet locked syndrome." Wearing a seat belt reduces the risk of severity. It is most often associated to lumbosacral joint fracture dislocation. Spondylolisthesis was classified by Wiltse and al. into dysplasic, isthmic, degenerative, pathologic and traumatic types [2]. Acute traumatic type is very rare [3]. The aim is to report a rare case of Traumatic spondylolisthesis at L4-L5 level and discuss its mechanism and management.

\section{Material methods}

The case report is followed by Literature Review. Literature review is made on Medline and scholar google

* Correspondence: ndriokad@gmail.com

Neurosurgery Department, Teaching Hospital of Yopougon, 21 BP 632 Abidjan, Côte d'Ivoire database from 2005 to 2015. We focused our interest on the number of cases, the Sex, the mechanisms, the level L4/L5 and the outcome.

\section{Results}

Case report

A 33-year-old patient, a driver of a tow truck, was admitted to the Neurosurgical Emergency unit for lumbar spine trauma. The injury was consecutive to a road traffic accident, which caused the vehicle to roll over several times. The patient was stuck inside the truck. Transportation to the neurosurgical emergency unit was not medicalized. Neurological examination revealed a paraparesis predominantly distal scored $3 / 5$ and urinary incontinence. Lumbar spine CT scan revealed spondylolisthesis at L4-L5. The spondylolisthesis was not associated with facet fracture (Fig. 1).

\section{Operative procedures and intraoperative findings}

After a reduction maneuver laminectomy of L4 and L5 vertebrae was performed. The laminectomy was completed by osteosynthesis. Osteosynthesis was realized 

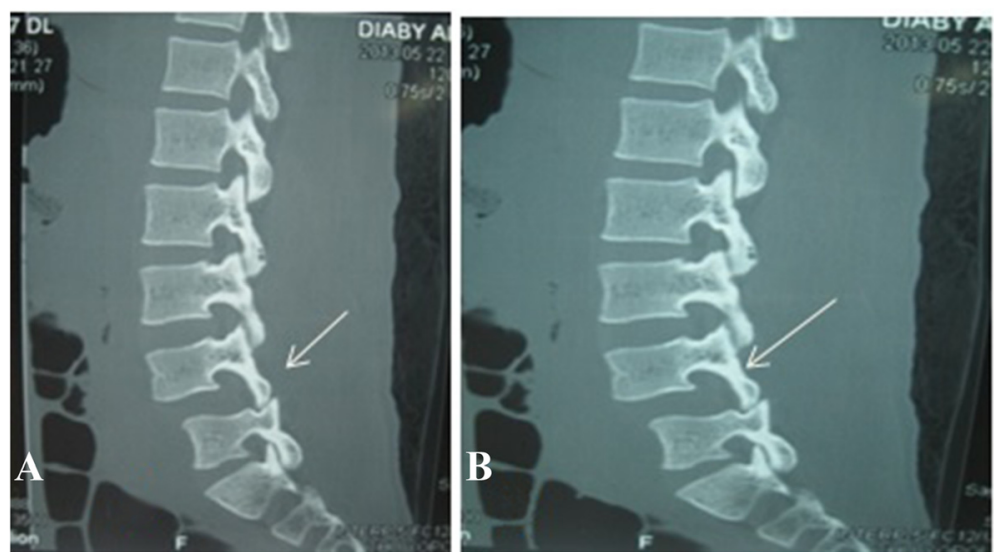

Fig. 1 Sagittal and CT scan view showing bilateral luxation a the right $\mathbf{b}$ the left view

with four screws connected by parallel rods. An intersomatic cage was set up after a discectomy L4-L5 (Fig. 2). Surgical treatment showed the ruptured L5 disc and posterior ligaments. Several physiotherapy sessions were prescribed.

\section{Post operative course}

Two months later the patient was walking using a walking frame. After decline in the disease 16 months later, the patient had a complete autonomy walking. Radiographic control revealed ruptured lower screws and of the upper screw head and nut (Fig. 2). The cage was still in place.

\section{Literature review [4-7] (Table 1)}

Literature review found five cases of traumatic lumbar locked facet syndrome at L4-L5. The series is composed of two women and four men. Improper use of seat belt was the cause in one case. Surgical treatment consisted of posterolateral interbody fusion. The post-operative period was even-free.

\section{Discussion}

The first case of L4-L5 traumatic spondylolisthesis was reported in 1940 by Watson Jones [1]. L4-L5 traumatic spondylolisthesis are quite unusual. The most frequent reported location is at L5-S1 [4]. In all of these reported cases traumatic spondylolisthesis was caused by improper use of a seat belt. The seat belt was without abdominal strap. Traumatic spondylolisthesis of the spine as a result of improper use of seat belt is considered as pathology of the seat belt without abdominal strap. L4-L5 traumatic ante-rolisthesis and retrolisthesis have similar physio pathological mechanism [8]. The direct shearing force at the lower lumbar area is also a major cause. The high-energy trauma produced disruptions of the posterior ligamentous structures; the facet sand the vertebrae body fractures, and anterior

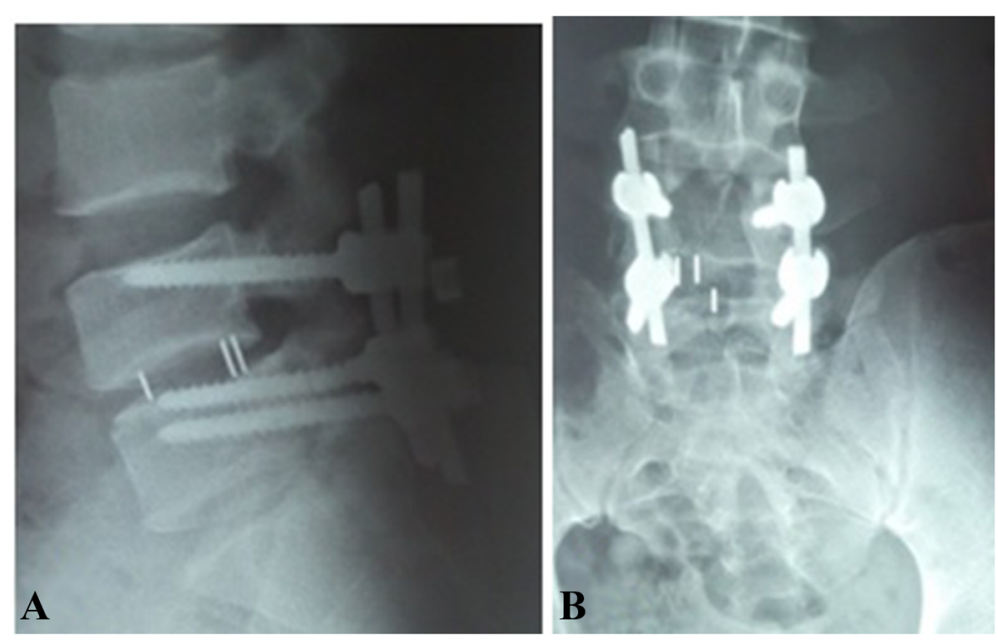

Fig. 2 Lumbar spine $x$-ray 16 months after lumbar spine osteosynthesis a lateral view and $\mathbf{b}$ front of view 
Table 1 Literature review from 2000 to 2015

\begin{tabular}{|c|c|c|c|c|c|c|c|}
\hline $\mathrm{Nb}$ & References & $\begin{array}{l}\text { Age/Sex } \\
\text { (years) }\end{array}$ & Mechanisms & Clinics & Imaging (MRI + CT scan) & Treatment & Outcome \\
\hline 1 & Mori et al. 2002 [4] & $32 / F$ & $\begin{array}{l}\text { Road Traffic accident } \\
\text { Seat belt in an improper manner } \\
\text { (vehicle driver) }\end{array}$ & $\begin{array}{l}\text {-No motor deficit } \\
\text {-Severe pain in her abdomen and } \\
\text { lower back } \\
\text {-No sphincter disorder }\end{array}$ & $\begin{array}{l}\text {-Disruption of intervertebral disk } \\
\text { and posterior longitudinal ligament } \\
\text { at L4-L5 } \\
\text {-Fracture of the right L4-L5 transverse } \\
\text { processes }\end{array}$ & $\begin{array}{l}\text { decompression and posterior } \\
\text { stabilisation + lumbar interbody fusion }\end{array}$ & -Good \\
\hline 2 & Lin et al. 2009 [5] & $41 / \mathrm{M}$ & $\begin{array}{l}\text { Work accident (Container } \\
\text { fell onto his back) }\end{array}$ & $\begin{array}{l}\text {-Lower limb Hypertonia } \\
\text {-hyporeflexia of the knee and } \\
\text { ankle reflexes-reduction sensation } \\
\text { over his right lateral leg } \\
\text {-low back pain } \\
\text {-Saddle anaesthesia }\end{array}$ & $\begin{array}{l}\text {-Fracture of the anterior-superior corner } \\
\text { of } L 5 \text { associated with a Chance-type } \\
\text { fracture } \\
\text {-dislocation through the } L 4 / 5 \text { disc } \\
\text { space and bilateral perched facets } \\
\text { with grade } 2 \text { spondylolisthesis of } L 4 \\
\text { on } L 5 \text {.grade- } 2 \text { spondylolisthesis of } \\
L 4 \text { on } L 5 \text { and a fracture of the left } \\
\text { transverse process of } L 4\end{array}$ & $\begin{array}{l}\text { Decompressionposterior stabilisation } \\
\text { +lumbar interbody fusion }\end{array}$ & $\begin{array}{l}\text {-Delayed } \\
\text { urinary } \\
\text { retention }\end{array}$ \\
\hline 3 & $\begin{array}{l}\text { Cordero-Abadía } \\
\text { et al. } 2012 \text { [6] }\end{array}$ & 18/M & Road Traffic accident & Member deficit motor of inferior & $\begin{array}{l}\text {-Spondylolisthesis at } L 4-L 5 \text { grade } \\
\text { I-Fracture of trensverse }+ \text { spinous } \\
\text { process } L 4\end{array}$ & $\begin{array}{l}\text { descompression and posterior } \\
\text { instrumentation inferior member motor } \\
\text { deficit at } 2 / 5 \text {. }\end{array}$ & -Good \\
\hline 4 & Im et al. 2012 [7] & $37 / M$ & $\begin{array}{l}\text { Work accident (held down } \\
\text { by aniron plate weighing } \\
2000 \mathrm{~kg} \text { ) }\end{array}$ & $\begin{array}{l}\text { Grade } 4 \text { numbness in his right } \\
\text { posterolateral thigh dorsiflexion }\end{array}$ & $\begin{array}{l}\text {-Epidural hematoma at the } L 2 \text { to } \\
L 5 \text { level and } L 4-L 5 \text { disc disruption } \\
-B \text { ilateral } L 4-5 \text { facet dislocation in } \\
\text { which the } L 4 \text { inferior articular process } \\
\text { was localizated to the anterior of the } \\
L 5 \text { superior articular process }\end{array}$ & $\begin{array}{l}\text { Open reduction and stabilization } \\
\text { interspinous ligaments and ligament } \\
\text { flavum were partially torn and the } \\
L 4-5 \\
\text { Facets were locked The dislocation } \\
\text { was reduced by resecting the superior } \\
\text { facet of } L 5 \text { and laminectomy of } L 4 \text { was } \\
\text { carried out. } \\
\text {-interbody fusion with cages, } \\
\text { +Fixation epidural hematoma }\end{array}$ & -Good \\
\hline 5 & $\begin{array}{l}\text { Present case report } \\
2015\end{array}$ & $33 / \mathrm{M}$ & Vehicle driver & Motor deficitUnary retension & $\begin{array}{l}\text {-Spodylolisthesis L4-L5 } \\
\text {-Facets were locked } \\
\text {-No fracture of facet }\end{array}$ & $\begin{array}{l}\text { Reduction by resecting the superior } \\
\text { facet of } L 5+\text { laminectomy of } L 4 \text {. Posterior } \\
\text { fixation interbody fusion with cages }\end{array}$ & -Good \\
\hline
\end{tabular}


sliding of the L4 vertebrae body, which resulted in a great instability of Denis's 3 columns. Traumatic spondylolisthesis at L4-L5 is associated with incorrect use of a three-point seat belt. Lumbar facet joints anatomy play major role in L4-L5 traumatic spondylolisthesis. The mechanism of injury seems to be forcible hyperextension $[8,9]$. However, hyperflexion with varying degrees of distraction is the most frequent mechanism of facet dislocation in the lumbar spine $[4,10,11]$. Hyperflexion alone is able to produce either pure dislocation or fracture-dislocation in the lumbar spine [9]. Therefore, in this case, we consider that, the mechanism of injury was a combination of hyperflexion, distraction, and rotation. The hyper-sagitalisation of superior articular processes could be the main factor that prevents the occurrence of dislocations [11]. Paravertebral lumbar muscles play a potential role in lumbar stability [10]. There are disruptions of the posterior ligamentous complex associated with facet dislocation [5, 7, 12]. Any fortuitous discovery of fractures of the transverse processes should warrant a search for a lumbar dislocation and vice versa. Moreover, the frontal orientation of S1 upper articular process almost always triggers a dislocation to the L5-S1 joint [8]. However, the iliolumbar ligament serves as a bulwark to prevent this type of traumatic injury. In our case report the mechanism is different because the driver was not thrown out of his vehicle. Hyperflexion of the trunk could explain the L4-L5 dislocation. The unusual L4-L5 level facet interlocking was attributed to the misuse of the automobile shoulder harness. It is important to recognize this injury and follow up on such clues.

The exploration must be multidirectional with 3D CT scan. A careful clinical examination and analysis of CT scan or MRI result in a diagnosis of lumbosacral dislocations. Meticulous clinical examination and careful imaging assessment, including CT scan and MRI, provide an early diagnosis in cases of lumbosacral dislocation [12]. MRI demonstrates a disruption of the posterior ligamentous $[3,12,13]$. Initially the treatment is conservative and involves hospitalization with bed rest and more analgesics; then surgical treatment is indicated. Lumbar spine trauma occurred during road traffic accident. In our report the transportation of patient to the neurosurgical emergency unit was not medicalized. The injuries initially without gravity could become significant with sensory-motor deficits. They will leave high sequelae despite prompt and adequate surgery. Finally, surgical treatment was a L4-L5 laminectomy, cage, and fixation by four pedicular screws connected by two parallel rods. Open reduction and circumferential bony fusion restored segmental stability and painless function [13]. The patient was mobilized in an armchair after two days of a total resolution of the painful symptoms.
Methods used by most authors lead to a favorable outcome. The introduction of early physiotherapy promotes rapid recovery in the event of a sensory-motor deficit. In our case the patient benefited from therapy sessions from the seventh day of his surgery. Two months later, he could walk with a walking frame. This reinforces hypothesis that early physiotherapy sessions in the event of sensory-motor deficit would promote recovery without sequelae. The sphincter disorders as acute urinary retention are not frequently associated with neurological disorders of lumbar dislocation L4-L5. Sphincter disorders regression are earlier than motor ones. Unlike the present case, acute retention of urine persisted beyond three months before disappearing. Once again the interest of physiotherapy as soon as possible. After 25 months the patient had no neurologic deficit. He was pain-free and had no restriction of mobility of lumbosacral spine. The radiograph revealed the release of a screw head associated with a rupture of one of L5 pedicle screw dislocation. Some authors report early decompression of the spinal cord performed at $24 \mathrm{~h}$ in dogs, the improvement in somatosensory evoked potentials was only $26 \%$, compared to 85 and $72 \%$ improvement achieved when decompression was carried out immediately and one hour after injury, respectively [14].

\section{Conclusions}

L4-L5 traumatic spondylolisthesis is rare, when it happens; physicians should always systematically search for fracture of the lumbar transverse processes. Meticulous clinical examination and careful imaging assessment, including CT scan and MRI, assist with an early diagnosis in cases of lumbosacral dislocation. Open reduction and circumferential bony fusion; restore segmental stability and painless function.

\section{Competing interests \\ The authors declare that they have no competing interests.}

Authors' contributions

DNO has performed the surgery, evaluated the patient, and drafted and revised the manuscript. SIS evaluated the patient, carried out the literature review. LK assisted the surgeon at the operation room. HY evaluated the patient, carried out the literature review. All authors read and approved the final manuscript.

\section{Acknowledgements}

We thank Sir DJO Bl and Doctor Alban Mbende who revised the English langue.

Received: 11 September 2015 Accepted: 26 November 2015 Published online: 18 March 2016

\footnotetext{
References

1. Watson-Jones R. Fractures and joint injuries. 1st ed. Baltimore: Williams \& Wilkins; 1940. p. 641

2. Wiltse LL, Newman PH, Macnab I. Classification of spondylolysis and spondylolisthesis. Clin Orthop. 1976;117:23-9.

3. Lim CT, Hee HT, Liu G. Traumatic spondylolisthesis of the lumbar spine: a report of three case. J Orthop Surg. 2009;17(3):361-5.
} 
4. Mori K, Hukuda S, Katsuura A, Saruhashi Y, Asajima S. Traumatic bilateral locked facet at L4-5: report of a case associated with incorrect use of a three-point seat belt. Eur Spine J. 2002;11(6):602-5.

5. Cordero-Abadía JH, Murillo-Villarino A, Núñez-Fernández Al, PosadasHernández FA, Rubio-González AA, Sesma-Villalpando RA. [Traumatic spondyloptosis of L4-L5. A case report and literature review]. Acta Ortop Mex. 2012;26(1):49-52

6. Im SH, Lee KY, Bong HJ, Park YS, Kim JT. Bilateral locked facets at lower lumbar spine without facet fracture: a case report. Korean I Spine. 2012;9(3):278-80.

7. Ahmed A, Mahesh BH, Shamshery PK, Jayaswal A. Traumatic retrolisthesis of the L4 vertebra. J Trauma. 2005;58:393-4.

8. Saiki K, Hirabayashi S, Sakai H, Inokuchi K. Traumatic anterior lumbosacral dislocation caused by hyperextension mechanism in preexisting $L 5$ spondylolysis: a case report and a review of literature. J Spinal Disord Tech. 2006;19(6):455-62.

9. Roaf R. A study of the mechanics of spinal injuries. J Bone Joint Surg (Br). 1960;42-B(4):810-23.

10. Hilibrand AS, Urquhart AG, Graziano GP, Hensinger RN. Acute spondylolytic spondylolisthesis. Risk of progression and neuro- logical complications. J Bone Joint Surg Am. 1995;77(2):190-6.

11. Zoltan JD, Guilula LA, Murphy WA. Unilateral facet dislocation between the fifth lumbar and first sacral vertebrae: case report. J Bone Joint Surg Am. 1979;61:767-9.

12. Zhou TH, Tang X, Xu YQ, Zhu YL. Traumatic spondyloptosis of $L 4$. Spine. 2010;35:E855-9.

13. Amesiya R, Orwotho N, Nyati M, Mugarura R, Sabakaki Mwaka E. Traumatic spondyloptosis of the lumbar spine: a case report. J Med Case Rep. 2014;8:453.

14. Delamarter RB, Sherman J, Carr JB. Pathophysiology of spinal cord injury. Recovery after immediate and delayed decompression. J Bone Joint Surg Am. 1995;77:1042-9.

\section{Submit your next manuscript to BioMed Central and we will help you at every step:}

- We accept pre-submission inquiries

- Our selector tool helps you to find the most relevant journal

- We provide round the clock customer support

- Convenient online submission

- Thorough peer review

- Inclusion in PubMed and all major indexing services

- Maximum visibility for your research

Submit your manuscript at www.biomedcentral.com/submit 